\title{
Magnetic Treatment For AMelioration OF WASTEWATER BIODEGRADATION
}

\author{
LiPUS, L.C.; HAMLER, A.; BUCHMEISTER, B. \& GORSEK, A.
}

Abstract: Nitrogen removal from wastewaters is highly important for environmental protection and human health. Recent findings about positive effect of a relatively weak magnetic field on microbial and enzymatic activity are opening new research fields, also on amelioration of wastewater biodegradation processes. Different models of magnetic devices were simulated with OPERA 17RI Vector Fields Software and constructed with adjustable magnetic field strength, for laboratory tests on wastewater biodegradation to find an efficient treatment regime. Total nitrogen removal in lab-bioreactor was enhanced by direct exposure of synthetic wastewater (inoculated with active sludge) to a static magnetic field at strength (30 to 50) $\mathrm{mT}$, indicating positive impact onto ammonium oxidizing bacteria. Similar effect was observed by inducing the recirculation of wastewater through the alternating magnetic field with peak strength $50 \mathrm{mT}$.

Key words: magnetic devices, simulation, modelling; wastewater; biodegradation
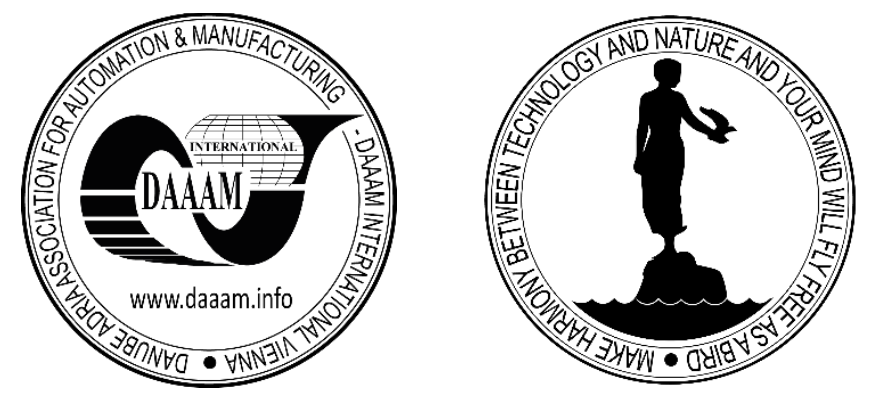

Authors' data: Assist. Prof. Lipus, C[repinsek] L[ucija]*, Univ. Prof. Hamler, $\mathrm{A}[\mathrm{nton}]^{* *}$, Univ. Prof. Buchmeister, B[orut]*, Univ. Prof. Gorsek, A[ndreja]***, *Faculty of Mechanical Eng., **Faculty of Electrical Engineering and Computer Science, ***Faculty of Chemistry and Chemical Engineering, University of Maribor, Smetanova 17, 2000 Maribor, Slovenia; lucija.lipus@um.si, anton.hamler@um.si, borut.buchmeister@um.si, andreja.gorsek@um.si

This Publication has to be referred as: C. Lipus, L[ucija]; Hamler, A[nton]; Buchmeister, B[orut] \& Gorsek, A[ndreja] (2018). Magnetic Treatment for Amelioration of Wastewater Biodegradation, Chapter 09 in DAAAM International Scientific Book 2018, pp.097-106, B. Katalinic (Ed.), Published by DAAAM International, ISBN 978-3-902734-19-8, ISSN 1726-9687, Vienna, Austria

DOI: $10.2507 /$ daaam.scibook.2018.09 


\section{Introduction}

Wastewaters need careful treatment before being discharged safely into the environment. A typical municipal sewage treatment plant includes primary treatment to remove solid material, secondary treatment to remove dissolved, suspended organic material, and disinfection. Microbial degradation during the second phase includes anaerobic and aerobic processes using activated sludge. Organic-nitrogen pollutant is converted into ammonium followed by nitrification and de-nitrification, finally released into the air as nitrogen gas; while organic carbon is oxidized gradually into carbon dioxide. Industrial wastewaters need additional treatment for degradation of specific toxic components, such as oil pollutants, phenols (Kriklavova et al. 2014) and formaldehyde (Lebkowska et al., 2011), due to their high persistency within the environment and the food chain (Buzoianu and Coloja, 2012).

Increasing pressure to meet more stringent discharge postulations (i.e. standards for Chemical Oxygen Demand (COD), Total Nitrogen (TN), and specific toxic components) have led to the implementations of a variety of advanced biological treatment processes (Tramsek et al., 2008; Bouskova et al., 2011). There are also new ideas about how to support biodegradation activities by alternative methods, for instance by exposure to a Magnetic Field (MF), which has working principle apart from the simple influence of the magnetic field on dispersed magnetic particles (Ravnik et al., 2017; Zielinski et al., 2018).

A number of studies have already appeared in the literature about the noticeable influences of MF on microorganisms, their viability and metabolism. In general, the potential use is either for preventing or enhancing purposes, depending on the organic species and treatment regime, e.g. strength and type of MF (static, pulsating), and length of exposure. For instance, the growth of Escherichia coli, Leclercia adecarboxylata and Staphylococcus aureus was inhibited by exposure to the pulsating $(50 \mathrm{~Hz}) \mathrm{MF}$ with strength $10 \mathrm{mT}$ (Fojt at al., 2004).

Static magnetic field exposure influenced the aerobic biosynthesis of polyhydroxyalkanoates by activated sludge: When the reactants were mixed or exposed solely to MF, maximal production of poly-3-hydroxybutyrate occurred at $7 \mathrm{mT}$, and of poly-3-hydroxyvalerate at $21 \mathrm{mT}$ (Chen and $\mathrm{Li}, 2008$ ). Several cases of increased enzymatic activity have been reported: Cellulase at $1 \mathrm{mT}, 50 \mathrm{~Hz}$ (Gao et al., 2011); glucose dehydrogenase and hexokinase at $300 \mathrm{mT}$, glycolytic enzymes at $0.1 \mathrm{mT}$, $50 \mathrm{~Hz}$ (Potenza et al., 2012); and dehydrogenase activity at formaldehyde removal, where biodegradation increased up to $20 \%$ at direct exposure to $7 \mathrm{mT}$ (Lebkowska et al., 2011). The growth of Escherichia coli and Pseudomonas putida, commonly found in municipal wastewater treatment plants, was inhibited during the exposure to static MF (17 mT) at their optimal growth temperature $(28$ and 37$){ }^{\circ} \mathrm{C}$, while the dehydrogenase activity was increased about 30 -times by MF and they viability was reversible shortly after the MF had been terminated (Filipic et al., 2012).

Some studies have already been reported about amelioration of wastewater biodegradation by exposure to a static MF of moderate strength. 
An enhancing effect on bacterial growth and metabolic behavior was observed in activated sludge, resulting in increased removal of organic pollutants, especially those containing nitrogen. A biodegradation of synthetic sewage (inoculated with activated sludge from a municipal wastewater treatment plant) increased up to $44 \%$, attributed to glucose degradation, at direct exposure to $18 \mathrm{mT}$ (Yavuz and Celebi, 2004); similarly, biodegradation of organic compounds in real municipal wastewater increased up to $40 \%$ at $20 \mathrm{mT}$ (Ji et al., 2010). An anaerobic TN removal in synthetic sewage with lab-cultivated anammox microbial population increased up to $50 \%$ at $75 \mathrm{mT}$ (Liu et al., 2008); similarly synthetic sewage with municipal sludge was increased at $48 \mathrm{mT}$ and the enhancement in growth and increased activity of nitriteoxidizing bacteria was proved (Wang et al., 2012). At lower temperatures (4 to 15$)^{\circ} \mathrm{C}$, the cold adaptability was enriched by MF, biodegradation of synthetic sewage with lab-cultivated sludge was increased at MF density in the range (20 to 40) $\mathrm{mT}$ (Niu et al., 2014). In the case of recirculating of synthetic sewage with municipal sludge through the MF with $40 \mathrm{mT}$, the biodegradation increased up to $16 \%$ (Tomska and Wolny, 2008).

Considering industrial pollutants, for enhancing the phenol biodegradation, a higher static MF strength was needed, e.g. by recirculation through static MF (250 to 370) mT the degradation increased by up to $34 \%$ (Kriklavova et al., 2012, 2014); while by inducing a pulsation of at least $50 \mathrm{~Hz}$, much weaker MF (20 mT) also increased the degradation up to $30 \%$. Promoted growth and activity of Rhodococcus erythropolis enhanced the phenol oxidation (Kriklavova et al., 2013).

How magnetic treatment influences the metabolism of microorganisms is not completely clear yet. MF re-orientates the diamagnetic anisotropic organic molecules, such as membrane lipids, changing the permeability of membrane ion channels (Rosen, 2003; Hughes et al., 2005). The explanation may be sought in hypotheses for other similar phenomena of magnetic water treatment that are related to modified hydration of ions and interface surfaces (Oshitani et al., 1999; Ohata et al., 2004).

The aim of the investigation reported here was to find a magnetic regime that would be technologically and financially applicable for bioreactors with higher capacities than the laboratory vessels which were used in most of reported investigations. Different MF models were analyzed with OPERA 17R1 Vector Fields Software using finiteelement operations (Lipus et al., 2012; 2015), for real operational data and material characteristics. Two magnetic devices were constructed with adjustable MF strength for laboratory tests, one for static exposure with homogenous MF and another for recirculation through the alternating MF.

\section{Magnetic devices for laboratory tests}

For experiments with continuous direct exposure of the reactor vessel to the MF, an excitation coil was found to be most suitable (Fig. 1). The excitation coil was composed of a solenoid coil and the Helmholtz coils (around the non-magnetic shell) to yield a homogeneous distribution of magnetic flux density $(B)$ inside the reactor vessel. 
In order to produce the static field, a Direct Current (DC) electricity supply was used and the MF strength was chosen differently by adjusting the electric-current strength during the experimental sets. The coil produces semi-homogeneous MF practically in the whole volume of the reactor vessel. Figs. 1.b and 1.c present two examples of $B$, about $37 \mathrm{mT}$ and about $75 \mathrm{mT}$, respectively. Fig. 1.d presents the relationship between the applied electric current, $I(\mathrm{~A})$, and $B(\mathrm{mT})$ measured inside the homogeneous region.

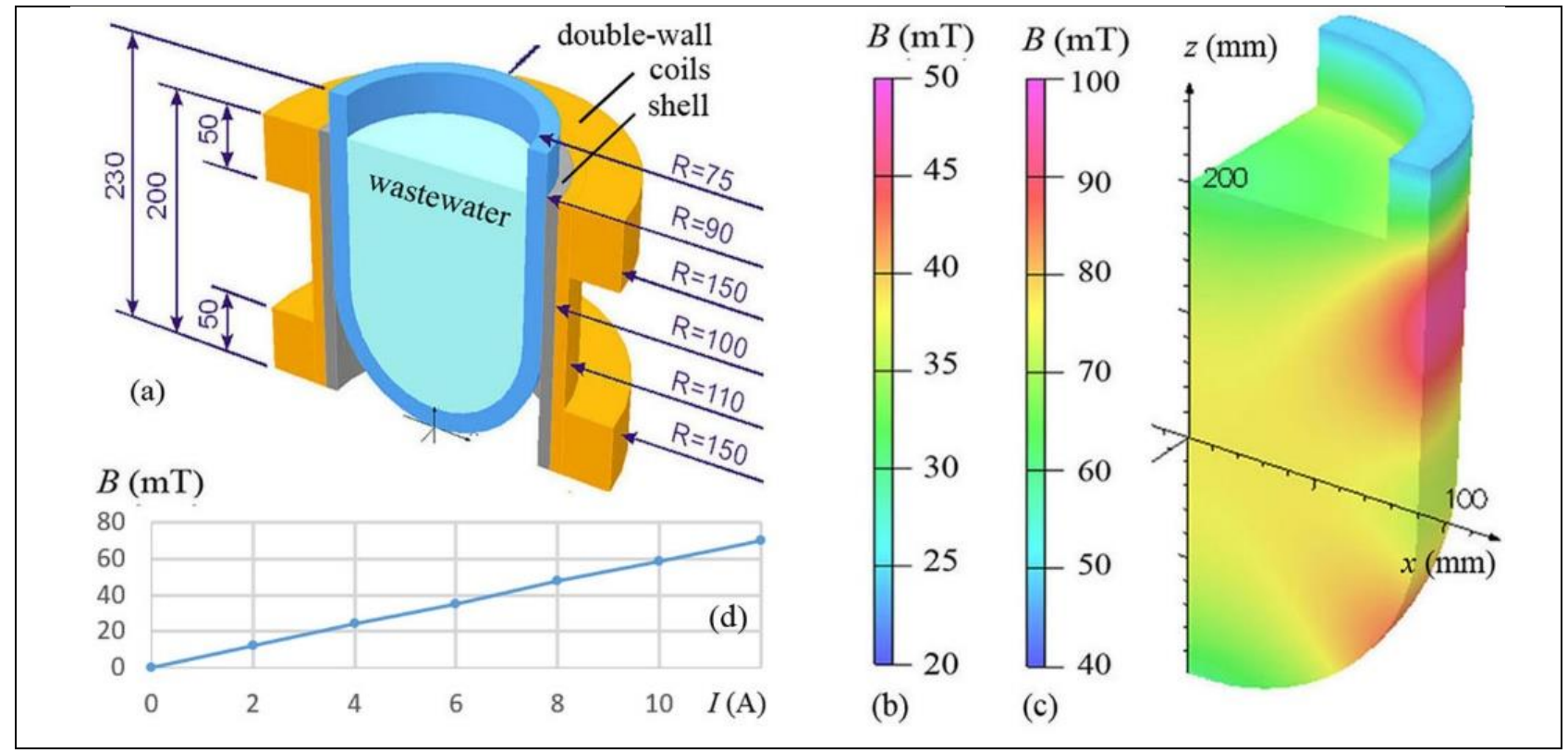

Fig. 1. Calculated distribution of magnetic flux density $B$ : (a) inside the double-walled vessel produced by the excitation coil $(R(\mathrm{~mm})$ are radii measured from the reactor's axis); (b) At 6 A, and (c) At 12 A of DC electricity supply; (d) Measured $B$ inside the reactor vs. DC electric current $I$.

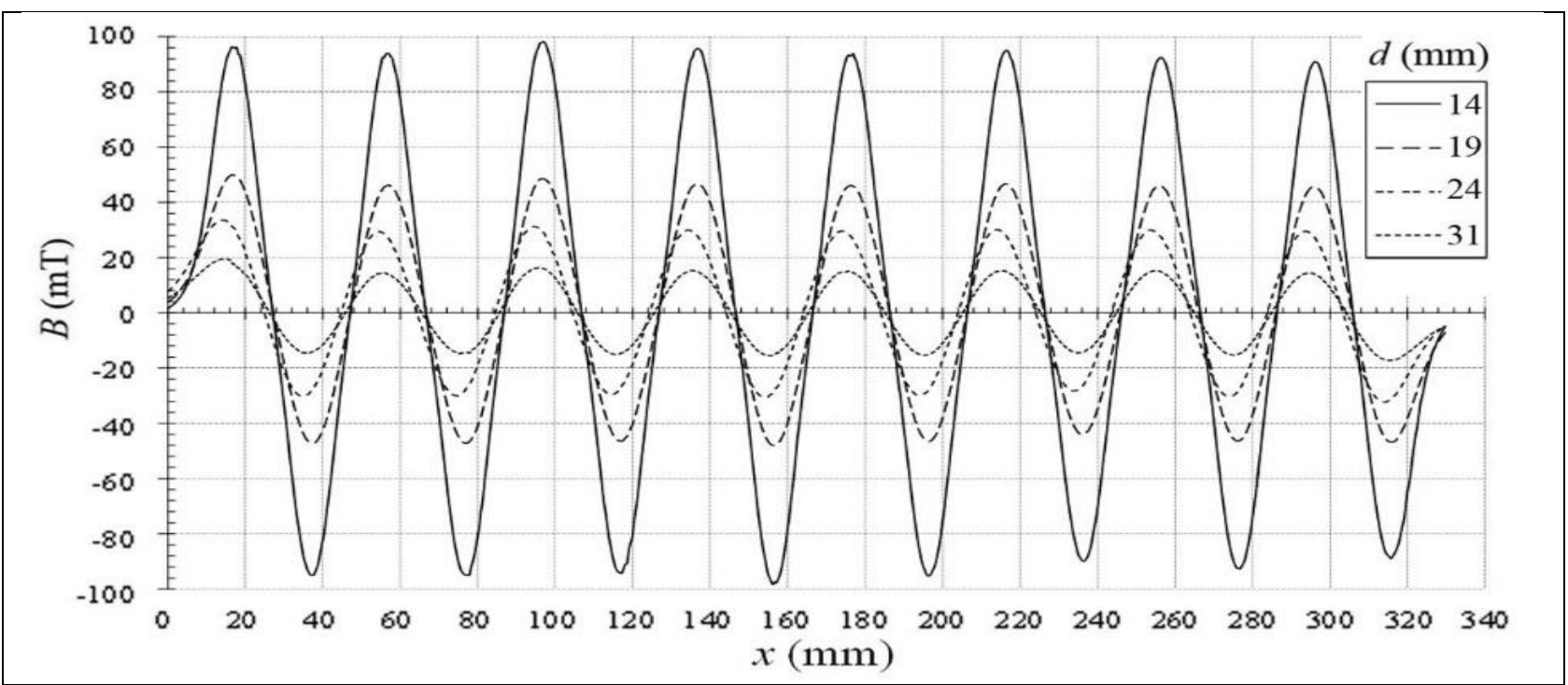

Fig. 2. Measured distribution of magnetic flux density $B$ along the channel-axis $x$ of alternating magnetic pairs (ferrite transversally magnetized magnets) at different distances inside pair $d$. 
For experiments with short-term magnetic treatment, a simple array of ferrite magnets, with an alternating orientation of MF lines was constructed (Fig. 2). Lowcarbonic steel was selected for the material of the magnetic yoke. The casting and the pipe must be non-magnetic. During the experimental sets, the magnetic field peaks were chosen differently by adjusting the distances, $d(\mathrm{~mm})$, inside the magnetic pairs.

\section{Experimental tests}

A batch regime was used for observation of MF influence on nitrogen removal. A lab-reactor was filled up with a mixture of synthetic wastewater $(8 \mathrm{~g}$ glucose, $0.4 \mathrm{~g}$ $\mathrm{NH}_{4} \mathrm{HCO}_{3}, 0.4 \mathrm{~g} \mathrm{KH}_{2} \mathrm{PO}_{4}, 0.4 \mathrm{~g} \mathrm{NaHCO}_{3}, 5 \mathrm{mg} \mathrm{MgSO} \cdot \mathrm{H}_{2} \mathrm{O}, 5 \mathrm{mg} \mathrm{FeCl}_{3}, 5 \mathrm{mg}$ $\mathrm{CaCl}_{2}, 5 \mathrm{mg} \mathrm{KCl}, 5 \mathrm{mg} \mathrm{CoCl} 2$ ), inoculated with activated sludge freshly taken from an aerated semi-batched basin at a municipal wastewater-treatment plant. Conditions within the basin vary throughout a season, due to city life-trends and weather; therefore, the runs were performed in short periods and simultaneously for comparison with and without magnetic treatment to provide similar viability and composition of microbial sludge. During the experiments, the effluent from the basin had $\mathrm{TN}=(3.5 \pm 1.5) \mathrm{mg} / \mathrm{L}$ and $\mathrm{COD} \approx 25 \mathrm{mg} / \mathrm{L}$; i.e. much better than the European Council Directive 91/271/EEC (since 1991, COD $<125 \mathrm{mg} / \mathrm{L}$ and $\mathrm{TN}<10 \mathrm{mg} / \mathrm{L}$, concerning urban wastewater treatment). No artificial organic-nitrogen components were added to the synthetic solution.

As the TN of the sludge samples was much smaller than in the synthetic solution, initially in the experiments TN was attributed mainly to the initial ammonium nitrogen, while the initial COD was attributed to the glucose. Ammonium removal occurs through the microbial nitrification-denitrification process: It is oxidized into $\mathrm{NO}_{2}{ }^{-}$ normally by autotrophic Nitrosomonas and further into $\mathrm{NO}_{3}^{-}$by autotrophic Nitrobacter; simultaneously the organic carbon is converted into carbon dioxide gas. Nitrate is then reduced into nitrogen gas by heterotrophic organisms, also releasing carbon dioxide gas using carbon from complex organic compounds. TN was sampled periodically from the vessel and analyzed on a Multi N/C 2100/2100s Analyzer, according to DIN 38409 - H27 and DIN EN 12260 Standards. Furthermore, a MERCK Spectroqant NOVA 60 photometer was used for ammonium determination. Total nitrogen concentration comprises the nitrogen concentration of ammonium, ammonium salts, nitrites, nitrates and organically-fixed nitrogen; while soluble nitrogen is undetected in this analytical method.

The operational conditions in the lab-vessel were maintained close to those in the actual basin during the current season, i.e. the summer. The vessel was double-walled to enable temperature stabilization $(21.5 \pm 0.5)^{\circ} \mathrm{C}$ by water-bath circulation; $p H$ was checked periodically, being $(7.2 \pm 0.2)$. The oxygen concentration was maintained at $(2.3 \pm 0.3) \mathrm{mg} / \mathrm{L}$ by pumping atmospheric air and dispersing within the vessel by stirrer. Firstly, the lab-reactor was inserted into the electromagnetic coil (Fig. 1), so the microorganisms could be exposed to the static MF continuously. A few preliminary runs with differently adjusted MF strength (Fig. 1.d) were performed to find a 
noticeable influence. At $30 \mathrm{mT}$ and $50 \mathrm{mT}$, an enhancement of TN removal was observed during the first hours (Fig. 3.a), which can be explained by increased viability of ammonium oxidative bacteria (Filipic et al., 2015).

Due to quick response of the activated sludge, a short-term magnetic treatment was induced by recirculation the wastewater mixture, through the array of alternating quadratic pairs of magnets (Fig. 2). A set of four-hour runs for differently adjusted MF strength showed the influence at peaks $50 \mathrm{mT}$ (Fig. 3.b, c). The result complies with the report on a similar treatment regime by Tomska et al., 2008.

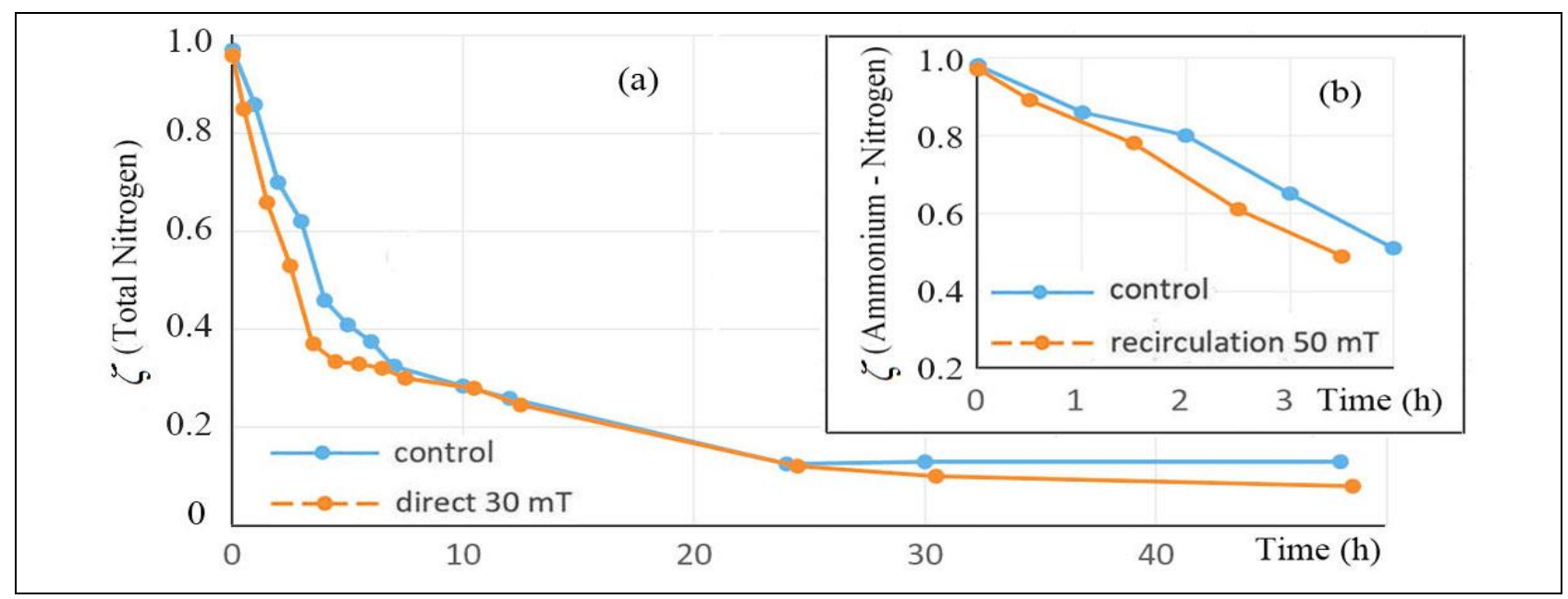

Fig. 3. Influence on the ammonium removal ( $\zeta$ is the mass concentration of nitrogen relative to the initial concentration): (a) Continuous exposure to static MF (30 mT); (b) Recirculation through the alternating MF (peaks $50 \mathrm{mT}$ ).

\section{Pilot tests}

When transferring the required treatment regime from lab- to pilot-level, the model with quadratic transversally magnetized magnets still can produce the required MF for pipe diameters up to $50 \mathrm{~mm}$ (Fig. 4), while for higher diameters, a model with hexagonal magnets is applicable (Fig. 5). The capacity can be also increased by the number of parallel arrays of magnets.

The short-term treatment regime by recirculation through the system of alternating quadratic magnets (MF peaks 50mT) was applied for further assessment at MikroChem LKT in the Czech Republic, the company for environmental protection and monitoring, pollution removal and wastewater disposal. Parallel runs (with and without MF) were performed for observation of phenol degradation rate (COD analysis) and of microbial growth (by optical density measurement). With MF, the shortening of lag-phase was observed and the growth rate of microbial population increased approx. $10 \%$ within first 3 days of the experiment. Due to positive results, the pilot unit (consisting of $1 \mathrm{~m}^{3}$ stirring reactor, two parallel biofilm-cultivation units, magnetic and control unit) was registered as $\mathrm{G}$ (prototype) - $\mathrm{Z}$ (verified technology), designated for cultivation of specific microbial populations for water or soil remediation, for removal of specific pollutants, e.g. phenols and petroleum hydrocarbons. 


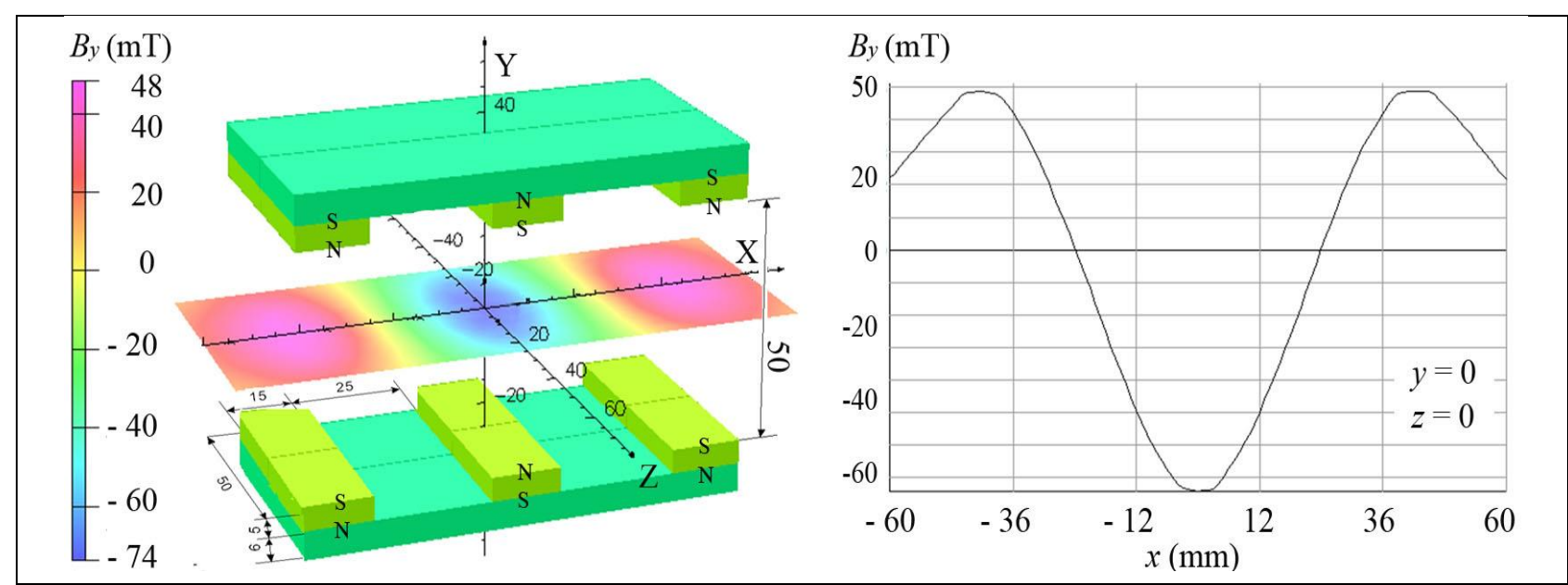

Fig. 4. MF distribution within the gap $50 \times 50 \mathrm{~mm}$, between rows of NdFeB magnets $50 \times 15 \times 5 \mathrm{~mm}$, on an iron plate, and $y$-component along the $x$-axis of the gap, $B y$.
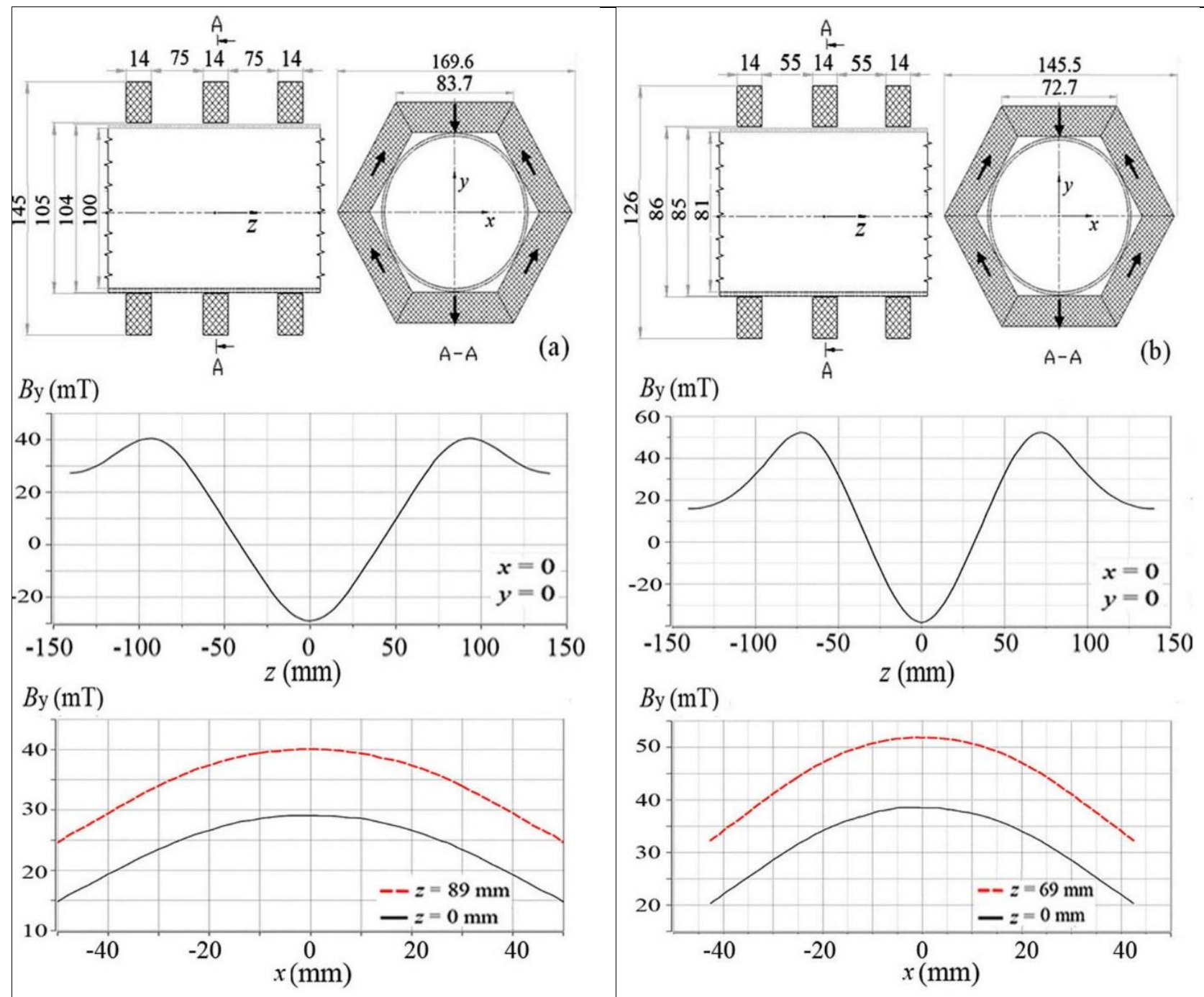

Fig. 5. Calculated distribution of MF strength inside the pipe surrounded by hexagonal $\mathrm{NdFeB}$ magnets (along the pipe $z$-axis and along the A-A cross-section: (a) Peaks $30 \mathrm{mT}$ at pipe diameter $100 \mathrm{~mm}$; and (b) Peaks $40 \mathrm{mT}$ at $81 \mathrm{~mm}$ diameter. 


\section{Conclusion}

Wastewater biodegradation depends on numerous process factors, such as the wastewater composition, temperature, aeration, flow regime, viability of activated sludge, and eventual presence of toxic components, such as pharmaceuticals. Restrictive criteria for wastewater disposal leads to high interest for implementation of advanced treatment regimes.

Novel methods for improvement of existing biological treatment process shall not require complete reconstruction or crucial changes of present treatment technology. In the view of economic and environmental applicability of the magnetic treatment as an alternative for amelioration of wastewater biodegradation, the capital costs of magnets or electricity consumption for electromagnetic coils shall be compared to savings in operational costs thanks to shorter start-up time and lower electricity consumption for the reactor aeration.

While the biological effects of strong MF, higher than $1 \mathrm{~T}$, have been relatively well studied, fewer reports can be found for effects at weaker MF. Limiting to TN and COD removal by aerobic biodegradation regime, in the majority the positive effects were observed at MF strengths (20 to 50) $\mathrm{mT}$, while $75 \mathrm{mT}$ was found to be effective for anaerobic anammox process. Due to different response of different microbial species, preliminary laboratory experiments are crucial for each individual case, to find the efficient MF strength and proper exposure time regarding the real biodegradation process factors. Our experiments were using a synthetic solution to provide proper experimental repeatability, inoculated with fresh sludge from an aerated semi-batched basin at municipal plant, to provide appropriate active microorganisms. The initial increase in TN removal observed at (30 to 50) $\mathrm{mT}$, can be explained by stimulation of the ammonium oxidizing bacteria. Regarding the quick response of activated sludge during the continuous exposure, a short-term magnetic treatment was also tested for MF strength and length.

In the view of technological applicability on semi-industrial level, the periodical stimulation of activated sludge can be induced by recirculation through a separate column surrounded by the electromagnetic coil. Another idea is a cultivation of target microorganisms on mobile biofilm-carriers in a separate bioreactor under continuous MF exposition, without any need for structural changes of the treatment plant.

The findings are opening a promising research field, with special focus on MF impact on enzymatic activity, and viability of target microorganisms that are capable for removal of specific industrial pollutants before effluent disposal. Our lab-magnetic devices are suitable for further investigations. We are planning to test the eventual MF impact on glucose oxidizing activity of immobilized enzymes.

\section{Acknowledgements}

The research was supported by the Project E! 4956 Magnet. Thanks to the Czech partners of the project Eureka LF 11016, especially to MikroChem LKT Ltd, Trebon. 


\section{References}

Bouskova, A.; Mrakota, J.; Stloukal, R.; Trögl, J.; Pilarova, V., Kriklavova, L.; Lederer, T. (2011). Three examples of nitrogen removal from industrial wastewater using Lentikats Biotechnology. Desalin., Vol. 280, No. 1-3, 191-196, ISSN 0011-9164 Buzoianu, D.-A.; Coloja, M.P. (2012). Diagnostic Analysis of Soils Contaminated with Oil and Salt Water, Standars for their Remediation, Annals of DAAAM for 2012 \& Proceedings of the 23rd International DAAAM Symposium, Vol. 23, No.1, ISSN 2304-1382, Ed. B. Katalinic, Published by DAAAM International, Vienna, Austria.

Chen, H.; Li, X. (2008). Effect of static magnetic field on synthesis of polyhydroxyalkanoates from different short-chain fatty acids by activated sludge. Bioresource Technology, Vol. 99, No. 13, 5538-5544, ISSN 0960-8524

Filipic, J.; Kraigher, B.; Tepus, B.; Kokol, V.; Mandic-Mulec, I. (2012). Effects of lowdensity static magnetic fields on the growth and activities of wastewater bacteria Escherichia coli and Pseudomonas putida. Bioresource technology, Vol. 120, Sep. 2012, 225-232, ISSN 0960-8524

Filipic, J.; Kraigher, B.; Tepus, B.; Kokol, V.; Mandic-Mulec, I. (2015). Effect of lowdensity static magnetic field on the oxidation of ammonium by Nitrosomonas europaea and by activated sludge in municipal wastewater. Food technology and biotechnology, Vol. 53, No. 2, 201-206, ISSN 1330-9862

Fojt, L.; Strasak, L.; Vetterl, V.; Smarda, J. (2004). Comparison of the low-frequency magnetic field effects on bacteria Escherichia coli, Leclercia adecarboxylata and Staphylococcus aureus. Bioelectrochem., Vol. 63, No. 1, 337-341, ISSN 1567-5394 Gao, M.; Zhang, J.; Feng, H. (2011). Extremely low frequency magnetic field effects on metabolite of Aspergillus Niger. Bioelectromagnetics, Vol. 32, No. 1, 73-78, ISSN 0197-8462

Hughes, S.; El Hai, A.J.; Dobson, J.; Martinac, B. (2005). The influence of static magnetic fields on mechanosensitive ion channel activity in artificial liposomes. European Biophysics Journal, Vol. 34, No. 5, 461-468, ISSN 0175-7571

Ji, Y.; Wang, Y.; Sun, J.; Yan, T.; Li, J.; Zhao, T.; Yin, X.; Sun, C. (2010). Enhancement of biological treatment of wastewater by magnetic field. Bioresource Technology, Vol. 101, No. 22, 8535-8540, ISSN 0960-8524

Kriklavova, L.; Kracikova, B. (2012). Degradation of phenol by Rhodococcus erythropolis in presence of magnetic fields. $5^{\text {th }}$ International Symposium on Biosorption and Bioremediation, Jun 24 - 28, Prague, Czech Republic, pp.131-134

Kriklavova, L.; Dub, T.; Truhlar, M.; Janousek, T.; Bohata, M.; Lederer, T. (2013). Effects of electromagnetic fields on bacteria Rhodococcus erythropolis. BioMicroWorld, V International Conference on Environmental, Industrial and Applied Microbiology, Oct 2 - 4, Madrid, Spain

Kriklavova, L.; Truhlar, M.; Skodova, P.; Lederer, T.; Jirku, V. (2014). Effects of a static magnetic field on phenol degradation effectiveness and Rhodococcus erythropolis growth and respiration in a fed-batch reactor. Bioresource Technology, Vol. 167, Sep 2014, 510-513, ISSN 1873-2976 
Lebkowska, M.; Narozniak-Rutkowska, A.; Pajor, E.; Pochanke, Z. (2011). Effect of a static magnetic field on formaldehyde biodegradation in wastewater by activated sludge. Bioresource Technology, Vol. 102, Mar 2013, 8777-8782, ISSN 0960-8524 Lipus, L.C.; Ačko, B.M; Hamler, A. (2012). Magnetic device simulation modelling and optimization for scale control. International Journal of Simulation Modelling, Vol. 11, No. 3, 141-149, ISSN 1726-4529

Lipus, L.C.; Hamler, A.; Ban, I.; Ačko, B. (2015). Permanent magnets for water-scale prevention. Advances in Production Engineering and Management, Vol. 10, No. 4, 209-216, ISSN 1855-6531

Liu, S.; Yang, F.; Meng, F.; Chen, H.; Gong, Z. (2008). Enhanced anammox consortium activity for nitrogen removal: Impacts of static magnetic field. Journal of Biotechnology, Vol. 138, No. 3-4, 96-10, ISSN 0168-1656

Niu, C.; Liang, W.; Ren, H.; Geng, J.; Ding, L.; Xu, K. (2014). Enhancement of activated sludge activity by $10-50 \mathrm{mT}$ static magnetic field intensity at low temperature. Bioresource Technology, Vol. 159, May 2014, 48-54, ISSN 0960-8524

Ohata, R.; Tomita, N.; Ikada, Y. (2004). Effect of a static magnetic field on ion transport in a cellulose membrane. Journal of Colloid and Interface Science, Vol. 270, No. 2, 413-416, ISSN 0021-9797

Oshitani, J.; Yamada, D.; Miyahara, M.; Higashitani, K. (1999). Magnetic effect on ion-exchange kinetics, J. Colloid Interf. Sci., Vol. 210, No. 1, 1-7, ISSN 0021-9797 Potenza, L.; Saltarelli, R.; Polidori, E.; Ceccaroli, P.; Amicucci, A.; Zeppa, S.; Zambonelli, A.; Stocchi, V. (2012). Effect of $300 \mathrm{mT}$ static and $50 \mathrm{~Hz} 0.1 \mathrm{mT}$ extremely low frequency magnetic fields on Tuber borchii mycelium. Canadian Journal of Microbiology, Vol. 58, No. 10, 1174-1182, ISSN 0008-4166

Ravnik, J.; Cernec, D.; Hribersek, M.; Zadravec, M. (2017). Magnetic Susceptibility Determination Based on Microparticles Sedimentation Analysis. International Journal of Simulation Modelling, Vol. 16, No. 2, 275-288, ISSN 1726-4529

Rosen, A.D. (2003). Effect of a $125 \mathrm{mT}$ static magnetic field on the kinetics of voltage activated $\mathrm{Na}^{+}$channels in $\mathrm{GH} 3$ cells. Bioelectromagnetics, Vol. 24, No. 7, 517-523; ISSN 0197-8462

Tomska, A.; Wolny, L. (2008). Enhancement of biological wastewater treatment by magnetic field exposure. Desalination, Vol. 222, No. 1-3, 368-373, ISSN 0011-9164 Tramsek, M.; Gorsek, A. (2008). Aerobic digester design for biodegradation of plant tannins in industrial wastewater. Chemical and Biochemical Engineering Quarterly, Vol. 22, No.1, 89-95; ISSN 0352-9568

Wang, X.-H.; Diao, M.-H.; Yang, Y.; Shi, Y.-J.; Gao, M.-M.; Wang, S.-G. (2012). Enhanced aerobic nitrifying granulation by static magnetic field. Bioresource Technology, Vol. 110, April 12, 105-110, ISSN 0960-8524

Yavuz, H.; Celebi, S.S. (2004). Influence of magnetic field on the kinetics of activated sludge. Environmental Technology, Vol. 25, No. 1, 7-13, ISSN 0959-3330

Zielinski, M.; Rusanowska, P.; Debowski, M.; Hajduk, A. (2018). Influence of static magnetic field on sludge properties, Science of the Total Environment, Vol. 625, June 1, 738-742, ISSN 0048-9697 